ISSN 1518-3483

Licenciado sob uma Licença Creative Commons

\title{
Educação do campo: materialidade da luta e signos discursivos
}

\author{
Rural education: materiality of \\ struggle and discursive signs
}

\begin{abstract}
Alex Verdério ${ }^{[a]}$, Ivete Janice de Oliveira Brotto ${ }^{[b]}$
[a] Graduado em Pedagogia para Educadores do Campo, Mestrando vinculado ao PPGE da Universidade Estadual do Oeste do Paraná (UNIOESTE), Cascavel, PR - Brasil, e-mail: alexverderio@yahoo.com.br

[b] Doutora em Educação pela Universidade Federal do Paraná (UFPR), professora vinculada aos colegiados dos cursos de Pedagogia e Pedagogia para Educadores do Campo e ao PPGE da Universidade Estadual do Oeste do Paraná (UNIOESTE), Cascavel, PR - Brasil, e-mail: ibrotto@brturbo.com.br
\end{abstract}

\section{Resumo}

Neste artigo objetivamos apresentar uma análise das palavras de ordem: "Educação do campo: direito nosso; dever do Estado!", as quais expressam a ação dos Movimentos Sociais Populares do Campo no Brasil na luta por uma educação do campo. As palavras de ordem, entendidas como signos discursivos, revelam a intencionalidade e a tensão produzida pelos sujeitos do campo no sentido da construção e concretização do que vem sendo chamado de educação do campo. Ancoramo-nos no referencial teórico-metodológico 
bakhtiniano, em especial na sua teoria da linguagem, para desenvolvermos a análise bibliográfica sobre a temática. Como orientação na luta, os signos discursivos - palavras de ordem - ao mesmo tempo em que conduzem os sujeitos, exigem-lhes o reposicionamento na luta de classe e na própria forma de fazer garantir o seu direito à educação. Esse posicionamento exige a tomada de consciência da contradição existente entre a ação dos trabalhadores organizados e a ação do Estado no trato e na concretização da educação do campo como política pública.

Palavras-chave: Luta de classes. Palavras de ordem. Educação do campo. Signo discursivo.

\section{Abstract}

This article aims at presenting an analysis of the watchwords "Rural education: our right; duty of the State!", which express the action of the Rural Social Movements in Brazil in the struggle for achieving the rural education. These watchwords, taken as discursive signs, reveal the intentionality and the tension produced by the peasants towards construction and achievement of the so-called rural education. The analysis is based on Bakhtin's theoretical framework, especially his theory of language. As a guide in the struggle, the discursive signs - the watchwords - lead the individuals to the class struggle, and also require their repositioning in this struggle and even in the way of ensuring their right to education. This positioning requires the awareness-raising concerning the contradiction between the action of organized workers and the action of State in dealing with, and achieving, rural education as a public policy.

Keywords: Class struggle. Watchwords. Rural education. Discursive sign.

\section{Introdução}

Nas últimas duas décadas a educação do campo (EdoC) tem sido colocada em pauta no contexto do debate educacional brasileiro pela força e organização dos Movimentos Sociais Populares do Campo 
(MSPsdo ${ }^{1}$ ), que focalizando os anseios e as necessidades dos indivíduos, dentro da luta social, têm possibilitado o aprendizado e a garantia de direitos à população oprimida que vive no campo brasileiro: "[...] pequenos agricultores, quilombolas, povos indígenas, pescadores, camponeses, assentados, reassentados, ribeirinhos, povos da floresta, caipiras, lavradores, roceiros, sem-terra, agregados, caboclos, meeiros, bóia-fria, e outros grupos mais" (CALDART, 2002, p. 25).

A luta por uma EdoC dá visibilidade a esses sujeitos, com suas características específicas. Entretanto, encontramos laços que os unem e os identificam como o povo brasileiro que vive no campo e tem sofrido na pele as marcas da opressão, discriminação e exploração impostas pelo capital.

Esses agentes sociais, os sujeitos do campo organizados e articulados nos MSPsdoC, são, por natureza, históricos, estão em movimento e se constituem como sujeitos coletivos. Dentro desse contexto, a EdoC não se restringe a determinado espaço geográfico. Ela considera as personagens desse local, o campo, como sujeitos capazes de construir um projeto educativo vinculado a um projeto de desenvolvimento, compartilhando o conhecimento a partir da realidade construída historicamente, em busca das transformações necessárias, para a emancipação humana.

Para tanto, o ponto de partida tomado são as práticas efetivadas por esses sujeitos, que a partir do contexto da luta de classes, de suas ações coletivas, vêm pressionando o Estado burguês na perspectiva da garantia de seus direitos, dentre eles o direito à educação, o que passa pelo redimensionamento das próprias condições de garantia de tais direitos. Os sujeitos aqui apontados estão imersos nas condições objetivas do campo brasileiro e de sua realidade concreta, que apresenta suas contradições,

${ }^{1}$ Ao utilizar o termo Movimentos Sociais Populares do Campo (MSPsdoC), conforme Titton (2006) e D’Agostini (2009), quando utilizam os termos 'movimentos sociais confrontacionais' e/ou 'movimentos de luta de classe', a perspectiva posta é a de compreender a atuação de determinados movimentos sociais classistas que se configuram no confronto direto com o capital, rompendo dessa forma com uma postura pós-moderna, que ao utilizar-se do termo 'novos movimentos sociais' deixa de lado a centralidade da luta de classes e desvincula a luta desses movimentos sociais da perspectiva de um projeto de sociedade contraposto ao da sociedade capitalista. 
de um campo que produz muita riqueza e também muita miséria, que inevitavelmente nos leva à totalidade do modo de produção capitalista.

A materialidade da EdoC e a presença constante dos MSPsdoC no contexto dos enfrentamentos entre trabalhadores e capital têm apontado a atuação na luta de classes como elemento fundamental na formação dos povos do campo que integram os MSPsdoC. Ao se encontrarem imersos na realidade de disputa presente no campo brasileiro, os sujeitos do campo, afligidos pelas consequências mais deploráveis do capitalismo, são levados a tomar posição no âmbito da luta de classes, o que os leva a configurarem-se como sujeitos, fruto da disputa entre os poucos que se apropriam das riquezas produzidas e os muitos explorados que vivem no campo brasileiro. Com isso materializam um fazer educativo que se firma principalmente no caráter educativo da própria luta de classes e no campo enquanto espaço de resistência dos camponeses diante do modo de produção capitalista. Conforme Caldart (2004, p. 84, grifos da autora), "há determinantes estruturais no modo como se pensa e se faz educação em cada período histórico, e no próprio processo de constituição dos sujeitos que experimentam essas condições e trabalham sobre elas”.

Considerando o contexto da luta pela terra e na terra e a constituição dos MSPsdoC, a busca da garantia da existência material, realizada por meio destes,

gera a necessidade de aprender a ser solidário e a olhar para a realidade desde a ótica do coletivo e não de cada indivíduo ou de cada família isoladamente. Uma inversão que não se aprende fácil e nem sem conflitos [...]. Mas um aprendizado que, quando se consolida, não deixa de se vincular com um profundo sentimento de indignação diante do contraste gritante que existe entre esta lógica de uma vida social baseada na competição e no individualismo desenfreados, exatamente os antivalores que sustentam uma sociedade que não se importa em produzir sem-terra, sem-teto, sem-emprego, sem-escola, sem-esperança... (CALDART, 2004, p. 179-180). 
Esse entendimento evidencia que a participação efetiva nos MSPsdoC, na luta de classes, imprime aspectos na vivência e no fazer educativo dos sujeitos do campo, que trazem em si uma grande possibilidade formativa. Tais aspectos, em suma, são traduzidos na produção de um aparato discursivo que, ao mesmo tempo em que materializa os anseios e as necessidades dos sujeitos envolvidos, passa pelo redimensionamento dessa materialidade, imprimindo um novo caráter na ação dos sujeitos.

\section{Educação no e do campo}

No fim da década de 1990 a EdoC, a partir da mobilização organizada dos povos do campo, seja nos MSPsdoC, seja nas organizações e entidades populares, com a efetivação prática de várias experiências educativas vinculadas à vida de tais sujeitos, fez com que o Estado fosse chamado a participar do debate acerca da EdoC. Conforme Caldart (2002, p. 27),

a educação do campo tem se desenvolvido em muitos lugares através de programas, de práticas comunitárias, de experiências pontuais. Não se trata de desvalorizar ou de ser contra estas iniciativas porque elas têm sido uma das marcas de nossa resistência. Mas é preciso ter clareza que isto não basta. A nossa luta é no campo das políticas públicas, porque esta é a única maneira de universalizarmos o acesso de todo o povo à educação.

A principal cunha dessa discussão, que efetivamente crava o debate da educação do campo na agenda educacional do País é o I Encontro Nacional de Educadores e Educadoras da Reforma Agrária (I Enera), ocorrido em 1997, organizado pelo Movimento dos Trabalhadores Rurais Sem Terra (MST), com o apoio, entre outras organizações, da Universidade de Brasília (UnB) e do Fundo das Nações Unidas para a Infância (Unicef). Esse evento toma por referência a Lei de Diretrizes e Bases (LDB) de 1996, que em seu artigo $1^{\circ}$ identifica que "[...] a educação abrange os processos formativos que se desenvolvem na vida familiar, na convivência humana, 
no trabalho, nas instituições de ensino e pesquisa, nos movimentos sociais e organizações da sociedade civil e nas manifestações culturais" (BRASIL, 1996, grifo nosso).

Os apontamentos feitos no I Enera geraram a necessidade de reorganização da agenda educacional brasileira e, em 1998, é organizada a I Conferência Nacional por uma Básica Educação do Campo, a partir da parceria entre MST, Unicef, Organização das Nações Unidas para o Desenvolvimento da Educação, Ciência e Cultura (Unesco) e Conferência Nacional dos Bispos do Brasil (CNBB). O evento funda o debate da EdoC, constituindo-se como

[...] ação que teve papel significativo no processo de rearticulação da questão da educação da população do campo para a agenda da sociedade e dos governos, e inaugurou uma nova referência para o debate e a mobilização popular: a Educação do Campo que é contraponto tanto ao silêncio do Estado como também às propostas da chamada educação rural ou educação para o meio rural no Brasil (DECLARAÇÃO..., 2004, p. 284).

No contexto da I Conferência Nacional da Educação do Campo e nas discussões posteriores esteve na ordem do dia o debate referente a uma educação do campo e no campo. Tal debate apontou para a necessidade de uma discussão que fosse contraposta à perspectiva da educação rural e, ao mesmo tempo, evidenciou a construção de uma proposta de educação que considera o modo de vida dos sujeitos do campo, este compreendido como espaço de vida e de relações.

Quando dizemos Por Uma Educação do Campo estamos afirmando a necessidade de duas lutas combinadas: pela ampliação do direito à educação e à escolarização no campo; e pela construção de uma escola que esteja no campo, mas que também seja do campo: uma escola política e pedagogicamente vinculada à história, à cultura, e às causas sociais e humanas dos sujeitos do campo [...] (DECLARAÇÃO FINAL..., 2002, p. 23, grifos do autor). 
Assim, a EdoC veio se constituindo, tendo por referência uma concepção de campo, na qual este figura como "[...] mais do que um perímetro não urbano, é um campo de possibilidades que dinamizam a ligação dos seres humanos com a própria produção das condições da existência social e com as realizações da sociedade humana" (BRASIL, 2002, p. 4). Isso implica conceber a escola do campo em uma nova perspectiva, pois

a identidade da escola do campo é definida pela sua vinculação às questões inerentes à sua realidade, ancorando-se na temporalidade e saberes próprios dos estudantes, na memória coletiva que sinaliza futuros, na rede de ciência e tecnologia disponível na sociedade e nos movimentos sociais em defesa de projetos que associem as soluções exigidas por essas questões à qualidade social da vida coletiva no país (BRASIL, 2002, p. 41-42).

A educação no e do campo vai para além da escola, entretanto tem na escola seu eixo central, o que gera o redimensionamento da própria escola e das relações que estabelece com o meio no qual está inserida.

\section{A linguagem e a luta de classes: uma análise acerca da EdoC}

No contexto da luta de classes, historicamente, os trabalhadores ao se organizarem em propósitos específicos, constroem e consolidam signos (palavras de ordem, símbolos e bandeiras de luta) que lhes conferem articulação, unidade e força na luta pelos seus direitos e, nesse movimento, possibilitam a produção da consciência de classe. Se tomarmos o que Marx e Engels (2002, p. 62), no Manifesto do Partido Comunista, sentenciaram com a máxima "Proletários de todos os países, uni-vos!", é possível perceber que as palavras de ordem podem potencializar e/ou solidificar, ora de maneira mais contundente, ora de maneira mais transitória, as características de luta e unidade na ação da classe trabalhadora em seu enfrentamento constante com as forças e interesses do capital. 
Esse entendimento aproxima-se da consideração de Bakhtin (2004), na qual o autor esclarece que serão convertidos em signos os elementos da realidade, natural ou social, cujo objeto, produto de consumo, corpo físico, etc. passarem a refletir e a refratar, além de si próprios, em certa medida, outra realidade. $\mathrm{O}$ mesmo ocorre em relação às palavras que, por serem signos e não meros sinais, ao serem ouvidas, ditas, lidas e servirem às diferentes e contraditórias classes e situações sociais, produzem deslocamentos de sentidos. Isto é, evocam juízos de valor, intenções, posicionamentos, transformam-se em arena de luta. Assim afirma Bakhtin (2004, p. 46): “o signo, se subtraído às tensões da luta social, se posto à margem da luta de classes, irá infalivelmente debilitar-se, degenerará em alegoria, tornar-se-á objeto de estudos dos filólogos e não será mais um instrumento racional e vivo para a sociedade".

Como fruto da história de luta da classe trabalhadora, os MSPsdoC, no Brasil, têm formulado e eleito palavras de ordem que conjunturalmente têm demonstrado sua unidade e habilidade de, por meio de signos, demonstrar o exercício constante de leitura da realidade objetiva, o que efetivamente os leva à tomada de posição, enquanto sujeito coletivo, perante a realidade da luta de classes. As palavras de ordem têm-se materializado na intervenção concreta na organização da luta; e, retornando aos sujeitos em luta, exige-lhes a afirmação ou concretização de uma nova postura. Assim, conforme Bakhtin (2004, p. 32),

um signo não existe apenas como parte de uma realidade; ele também reflete e refrata uma outra. Ele pode distorcer essa realidade, ser-lhe fiel, ou apreendê-la de um ponto de vista específico, etc. Todo signo está sujeito aos critérios de avaliação ideológica (isto é: se é verdadeiro, falso, correto, justificado, bom, etc.).

No âmbito da luta por uma EdoC, as palavras de ordem, como signos produzidos na luta de classes, têm produzido a unidade que demonstra a força com que os MSPsdoC passam a exigir do Estado a concretização dos direitos dos trabalhadores do campo. Por outro lado, elas, as palavras de ordem, retornam aos sujeitos do campo, exigindo destes o seu 
reposicionamento no contexto da luta, produzindo assim a consciência de classe, uma vez que, conforme Bakhtin (2004, p. 34-35):

a consciência adquire forma e existência nos signos criados por um grupo organizado no curso de suas relações sociais. Os signos são o alimento da consciência individual, a matéria de seu desenvolvimento, e ela reflete sua lógica e suas leis. A lógica da consciência é a lógica da comunicação ideológica, da interação semiótica de um grupo social. Se privarmos a consciência de seu conteúdo semiótico e ideológico, não sobra nada.

Sendo assim (e a prática tem demonstrado), as palavras de ordem têm tido efetiva tarefa na construção da consciência de classe entre os camponeses e trabalhadores que se põem em luta, nos MSPsdoC, na conquista dos direitos negados no e pelo capitalismo.

A existência do signo nada mais é do que a materialização dessa comunicação [social]. É nisso que consiste a natureza de todos os signos ideológicos.

[...] esse papel contínuo da comunicação social como fator condicionante não aparece [...] em nenhum lugar de maneira mais clara e completa do que na linguagem. A palavra é o fenômeno ideológico por excelência (BAKHTIN, 2004, p. 36, grifo do autor).

A palavra configura-se, assim, como ponto de apoio a outros signos ideológicos. Entretanto, esse fato não implica considerar que todo signo (em seu significado) possa ser substituído por palavras; significa entender que a palavra passa a auxiliar a compreensão e a interpretação de outros tantos determinados signos.

Desse modo, a palavra assume o caráter de primeiro meio propulsor da consciência individual. Por mais que, aparentemente, não tenha uma expressão exterior, o despertar da consciência não revele a condição social exterior, é essa condição que possibilita a internalização do pensamento individual e passa a figurar como signo interior de fundamental importância para a compreensão do mundo e das relações nas quais o 
sujeito individual está inserido. Como afirma Bakhtin (2004, p. 37), "na verdade a consciência não poderia se desenvolver se não dispusesse de um material flexível, veiculável pelo corpo. E a palavra constitui exatamente esse tipo de material".

Com essa compreensão, toma-se como elemento de análise a luta que vem sendo travada pelos MSPsdoC no intuito de exigir do Estado a consolidação de uma política pública de EdoC. Na II Conferência Nacional por uma Educação do Campo, realizada em agosto de 2004, a orientação da ação dos MSPsdoC em relação à luta por uma EdoC foi sistematizada na seguinte palavra de ordem: "Educação do campo: direito nosso; dever do Estado!". A partir daí a luta por uma EdoC passa a ser direcionada para a exigência da consolidação de uma política pública de EdoC, tendo em vista que,

[...] o universal tem sido pouco universal. O que se quer, portanto, não é ficar na particularidade, fragmentar o debate e as lutas; ao contrário, a luta é para que o "universal seja mais universal", seja de fato síntese de particularidades diversas, contraditórias (CALDART, 2008, p. 74).

E para que, de fato, esse universal universalize-se, faz-se necessária a luta no campo do direito, das políticas públicas. E implica uma concepção de direito como elemento concreto e não apenas jurídico como defendem muitos, pois, conforme nos lembra Arroyo (apud MOLINA, 2008), uma das tensões que hoje vivemos na defesa dos direitos é a destes serem defendidos apenas no campo jurídico, o que pode concorrer para sua não realização, especialmente porque o que vem efetivamente ocorrendo é a negação de direitos.

Temos que defender o direito à educação como direito universal, mas como direito concreto, histórico, datado, situado num lugar, numa forma de produção, neste caso da produção familiar, da produção agrícola no campo; seus sujeitos têm trajetórias humanas, de classe, de gênero, de etnia, de raça, em que vão se constituindo como mulheres, indígenas, negros e negras, como trabalhadores, produtores do campo... Os 
movimentos sociais nomeiam os sujeitos dos direitos. Esses sujeitos têm rosto, têm gênero, têm classe, têm identidade, têm trajetórias de exploração, de opressão. Os movimentos sociais têm cumprido uma função histórica no avanço dos direitos: mostrar seus sujeitos, com seus rostos de camponês, trabalhador, mulher, criança. Sujeitos coletivos concretos, históricos (ARROYO apud MOLINA, 2008, p. 27-28).

Apenas nomear os povos do campo como sujeitos de direitos não basta. Para a garantia concreta de direitos faz-se necessária a instituição de ações afirmativas no contexto das políticas públicas. Ao considerarmos a trajetória excludente e discriminatória da educação rural e a realidade da educação dos povos do campo em nosso País, tendo presente o alto índice de analfabetismo, por exemplo, a EdoC passa a constituir-se como uma dívida que precisa ser assumida pelo conjunto da sociedade. Conforme Molina (2008, p. 29), "é a especificidade das condições de acesso e as desigualdades históricas no acesso à educação que necessariamente demandam ações afirmativas do Estado para corrigir essas distorções". Se um grupo social não consegue acessar a educação, que é entendida como direito subjetivo de todos, o Estado tem a obrigação de assegurar políticas diferenciadas que garantam esse direito. As políticas educacionais devem ser universalizantes, e para tanto necessitam dar conta do específico, para que os direitos previstos nos documentos oficiais sejam acessados, como direito concreto, por determinados grupos vulneráveis da sociedade, possibilitando-lhes o acesso à educação, por exemplo.

Nesse sentido,

lutar por políticas públicas significa lutar pelo alargamento da esfera pública, lutar para que a educação não se transforme, como querem muitos hoje, em mercadoria, em um serviço, que só tem acesso quem pode comprar, quem pode pagar. Lutar por políticas públicas para a Educação do Campo significa lutar para ampliar a esfera do estado, para não colocar a educação na esfera do mercado. Nesse momento, entra novamente a questão da justiciabilidade do direito à educação dos povos do campo. Porque não se institui políticas enquanto elas não 
estão muito presentes no conjunto do imaginário da sociedade (MOLINA, 2008, p. 27, grifos nosso).

Nessa lógica, a luta pelo direito, no contexto da discussão aqui posta e empreendida pelos MSPsdoC, tem ultrapassado o limite do direito jurídico e se tem efetivado na luta pela concretização do direito real, concreto. Conforme Molina (2008, p. 28), “[...] o que se busca não é somente a igualdade de acesso 'tolerada' pelos liberais, mas fundamentalmente a igualdade de resultados".

A evidência material da busca pelo direito em sua concretização real, para além do direito jurídico, torna-se cotidiana na luta dos povos do campo. Nas ocupações, nas marchas, nas mobilizações de massa, nos estudos, na prática da solidariedade de classe, na dimensão da produção, da auto-organização, do trabalho cooperado, das lutas empreendidas contra o capital e contra o Estado. Com tais ações, os povos do campo passam a refletir sobre sua condição, pressionando, concomitantemente, o Estado no sentido de que este mostre sua face, para que a classe trabalhadora possa identificar seu real posicionamento em favor das classes dominantes. Coloca-se, assim, com esse entendimento, a possibilidade de a classe trabalhadora avançar na luta estratégica rumo à emancipação plena do ser humano.

Conforme Saes (1998), identifica-se na luta travada pelos MSPsdoC o que o autor denomina de ação legal-revolucionária, pois, ao mesmo tempo em que os povos do campo defendem e lutam pela instituição de políticas sociais, nesse caso específico a EdoC, passam a efetivar tais ações no sentido de desvelar o caráter classista destas, denunciando o caráter formal ilusório da igualdade política. A ação legal dos povos do campo tem-se constituído como ação legal-revolucionária. Esses sujeitos, na medida em que se utilizam dos mecanismos legais das instituições democráticas para o favorecimento de seus interesses específicos, pressionam o estabelecimento do elemento pedagógico da denúncia, levam ao limite a igualdade formal, expondo assim a impossibilidade dela constituir-se como caminho para a igualdade material. Esse exercício tem dado às populações do campo a condição de identificar o limite das políticas sociais do Estado. 
Retomando a palavra de ordem que passou a representar a efetiva luta pela concretização da EdoC como política pública, a partir da II Conferência Nacional por uma Educação do Campo, ao mesmo em que os MSPsdoC indicam que a EdoC é um direito dos povos do campo, também identificam que a disponibilização desta é um dever do Estado. Compreensão que tem atuação incisiva no fazer dos povos do campo, que passam a exigir do Estado esse direito e sua concretização com a instituição de políticas sociais.

As políticas públicas, que são realizadas na esfera das políticas sociais, configuram-se como consequência das tensões entre capital e trabalho, das quais o Estado lança mão para garantia da reprodução do capital e concomitante manutenção de seu status quo, em função dos avanços organizativos e de luta da classe trabalhadora. Dessa forma, as políticas sociais são

respostas do Estado burguês do período do capitalismo monopolista a demandas postas no movimento social por classes (ou estratos de classes) vulnerabilizados pela "questão social". [...] O Estado apresenta respostas quando os afetados por essas expressões são capazes de exercer, sobre ele, uma pressão organizada. Não basta que haja expressões da "questão social" para que haja política social; é preciso que aqueles afetados pelas suas expressões sejam capazes de mobilização e organização para demandar a resposta que o Estado oferece através da política social (PAULO NETO, 2003, p. 15-16).

Contudo, convém ressaltar que, ao mesmo tempo em que as políticas sociais são resultado efetivo da luta dos trabalhadores, constituem-se como empecilhos para o avanço organizativo da classe trabalhadora. É um movimento contraditório em que se percebe a interpenetração de opostos, trazendo novas sínteses. A implementação de políticas sociais que, a princípio, favoreceriam a classe trabalhadora e significariam perdas para os detentores dos meios de produção na medida em que a destinação dos recursos desvia-se do seu real interesse - a reprodução do capital -, na verdade, reverte-se em avanços para o capital. Nesses termos, o capital ganha porque, dada a necessidade constante de reprodução da força de 
trabalho para sua manutenção, as políticas sociais também têm efeito de desmobilização, de desarticulação e de imobilidade produzidos entre os trabalhadores, influenciando diretamente na formação da sua consciência de classe, perdendo estes. É nessa correlação de forças que se situa a luta entre capital e classe trabalhadora.

A contradição, presente no âmbito das políticas sociais, tem-se materializado na luta por uma EdoC. Os MSPsdoC, ao verem-se imbricados por essa contradição, foram levados a refletir sobre a própria palavra de ordem "Educação do campo: direito nosso; dever do Estado!", que significou essa pressão do direito dos povos do campo à educação com a luta pelo acesso a políticas públicas, entendendo-as como dever do Estado. Tal reflexão exigiu o redimensionamento da própria palavra de ordem, pois se a EdoC historicamente foi cravada na agenda educacional brasileira pela força organizativa de luta dos MSPsdoC, a contradição anunciada tem figurado como elemento central do debate em torno da EdoC. Entretanto, não bastaria identificar a EdoC como direito dos povos do campo e como dever do Estado. Isso não implicaria necessariamente sua realização no contexto real. Poderia apenas limitar-se a um direito jurídico, reconhecido constitucionalmente, não efetivado na materialidade da vida dos povos do campo. Esse foi o caráter emblemático da denominada educação rural, o qual foi disposto até o momento e passou a imprimir, junto aos povos do campo, a necessidade de sua organização nos MSPsdoC e exigir do Estado a realização do direito à educação.

A compreensão e a necessidade de atuação, no âmbito contraditório das políticas sociais, fez com que os MSPsdoC redimensionassem a própria luta pelo direito à educação, pois se, de fato, a EdoC é direito dos povos do campo e dever do Estado, este só irá realizar seu dever se os próprios povos do campo colocarem-se e se mantiverem em luta.

Assim, a compreensão passou a refletir-se na necessidade de reelaboração da palavra de ordem "Educação do campo: direito nosso e dever do Estado!", pois a EdoC, no contexto das políticas sociais e como direito concreto dos povos do campo, só se efetivará com compromisso e por meio da mobilização da comunidade camponesa em luta. Dessa compreensão materializa-se uma nova palavra de ordem: "Educação do 
campo: direito nosso; dever do Estado e compromisso da comunidade!". Esta, no contexto da $\mathrm{EdoC}$, evidencia que a materialidade produzida nas duas décadas de luta travada pelos MSPsdoC em relação a EdoC passa a imprimir o caráter da própria luta pelo direito à educação. Ou seja, as conquistas e os avanços obtidos, nesse caso específico das políticas públicas de $\mathrm{EdoC}$, retornam aos sujeitos do campo, exigindo-lhes reposicionamentos constantes no que se refere à luta de classes, para que o conquistado até agora não se perca e sejam possíveis novas conquistas.

Com a presente argumentação e análise identifica-se, conforme Bakhtin (2004), que o ser social, aqui os camponeses e trabalhadores organizados nos MSPsdoC, ao refletirem seus anseios e necessidades por meio dos signos que vão se firmando na luta de classes, não apenas neles são refletidos, mas também são refratados, ou seja, provocados a repensar a sua ação e o seu fazer de luta. O elemento determinante desse refletir do ser no signo, e dessa refração do signo no ser, está atrelado ao confronto de interesses sociais, o que implica a compreensão de que o signo constitui-se no terreno onde se desenvolve a luta de classes.

\section{Considerações finais}

Neste artigo, buscou-se discutir as intenções e as tensões colocadas na materialidade da luta por uma Educação do Campo e a ação dos Movimentos Sociais Populares do Campo no Brasil. Focou-se a discussão na análise dos signos discursivos colocados em evidência na palavra de ordem: "Educação do campo: direito nosso; dever do Estado!". A perspectiva de análise adotada permitiu verificar que ao mesmo tempo em que os signos são produzidos pelos povos do campo para garantia do seu direito à educação, incidem diretamente sobre eles nessa mesma luta, exigindo-lhes novos posicionamentos, na medida em que se conscientizam das contradições que suas ações são capazes de engendrar.

A construção e a concretização do que vem sendo chamado de educação do campo está expressa nas palavras de ordem que, como todo 
signo, refletem e refratam certa compreensão da realidade. O reposicionamento dos sujeitos na luta de classe e na própria forma de fazer garantir o seu direito à educação não ocorre sem uma conscientização dos trabalhadores sobre as contradições expressas, inclusive, por meio das políticas sociais, muitas vezes o resultado dessa mesma luta. Uma conscientização que abarca o conhecimento das possibilidades possíveis entre a ação dos trabalhadores organizados e a ação do Estado no trato e na concretização da educação do campo como política pública.

\section{Referências}

BAKHTIN, M. M. Marxismo e filosofia da linguagem: problemas fundamentais do método sociológico na ciência da linguagem. 11. ed. São Paulo: Hucitec, 2004.

BRASIL. Conselho Nacional de Educação. Resolução CNE/CEB n. 1, de 3 de abril de 2002. Institui Diretrizes Operacionais para a Educação Básica nas Escolas do Campo. Diário Oficial [da] República Federativa do Brasil, Poder Legislativo, Brasília, DF, 9 de abril de 2002. Seção 1, p. 32. Disponível em: <http://portal. mec.gov.br/cne/arquivos/pdf/CEB012002.pdf〉. Acesso em: 16 jul. 2010.

BRASIL. Lei n. 9.394/96, de 20 de dezembro de 1996. Estabelece as diretrizes e bases da educação nacional. Diário Oficial [da] República Federativa do Brasil, Poder Legislativo, Brasília, DF, 23 dez. 1996. p. 27833. Disponível em: <http://www6.senado.gov.br/legislacao/ListaTextoIntegral.action?id=75723 >. Acesso em: 23 jul. 2010.

CALDART, R. S. Por uma educação do campo: traços de uma identidade em construção. In: KOLLING, E. J.; CERIOLI, P. R.; CALDART, R. S. (Org.). Educação do Campo: identidade e políticas públicas. Brasília: Articulação Nacional por uma Educação do Campo, 2002. p. 25-36.

CALDART, R. S. Pedagogia do Movimento Sem Terra. 3. ed. São Paulo: Expressão Popular, 2004. 
CALDART, R. S. Sobre Educação do Campo. Educação do campo: reflexões a parir da tríade Produção - Cidadania - Pesquisa. In: SANTOS, C. A. dos (Org.). Por uma Educação do Campo: Campo - Políticas Públicas - Educação. Brasília: INCRA; MDA, 2008. p. 67-86.

D'AGOstini, A. A educação do MST no contexto educacional brasileiro. 2009. 205 f. Tese (Doutorado em educação) - Programa de Pós-Graduação em Educação da Faculdade de Educação da Universidade Federal da Bahia, Salvador, 2009.

DECLARAÇÃO FINAL DA II CONFERÊNCIA NACIONAL POR UMA EDUCAÇÃO DO CAMPO: Por uma política pública de educação do campo. Luziânia, Goiás, agosto de 2004. Inter-Ação: Rev. Fac. Educ. UFG, v. 29, n. 2, p. 283-293, 2004. Disponível em: <http://www.revistas.ufg.br/index.php/interacao/article/ viewFile/1418/1432>. Acesso em: 8 fev. 2010.

DECLARAÇÃO FINAL DO SEMINÁRIO NACIONAL POR UMA EDUCAÇÃO DO CAMPO. KOLLING, E. J.; CERIOLI, P. R.; CALDART, R. S. (Org.). Educação do campo: identidade e políticas públicas. Brasília: Articulação Nacional por uma Educação do Campo, 2002. p. 15-23.

MARX, K.; ENGELS, F. O manifesto comunista. 11. ed. Rio de Janeiro: Paz e Terra, 2002.

MOLINA, M. C. A constitucionalidade e a justicibilidade do direito à educação dos povos do campo. In: SANTOS, C. A. dos (Org.). Por uma educação do campo: Campo - Políticas Públicas - Educação. Brasília: INCRA; MDA, 2008. p. 19-31.

PAULO NETO, J. O materialismo histórico como instrumento de análise das políticas sociais. In: NOGUEIRA, F. M. G. Estado e políticas sociais no Brasil. Cascavel: Universidade Estadual do Oeste do Paraná - Campus Cascavel, 2003. p. 11-28.

SAES, D. Estado e democracia: ensaios teóricos. 2. ed. Campinas: Ed. da Unicamp; Instituto de Filosofia e Ciências Humanas, 1998. 
TITTON, M. Organização do trabalho pedagógico na formação de professores do MST: realidade e possibilidades. 2006. 183 f. Dissertação (Mestrado em educação) - Programa de Pós-Graduação em Educação da Faculdade de Educação da Universidade Federal da Bahia, Salvador, 2006.

Recebido: 31/05/2011

Received: 05/31/2011

Aprovado: 21/06/2011

Approved: 06/21/2011 